\title{
Activation energy for mullitization of gel fibres obtained from aluminum isopropoxide
}

\author{
HONGBIN TAN ${ }^{\mathrm{a}, \mathrm{b}, *}$, YAPING DING ${ }^{\mathrm{a}}$, HAIHONG ZHANG ${ }^{\mathrm{a}}$, JIANFENG YANG ${ }^{\mathrm{a}}$ and \\ GUANJUN QIAO ${ }^{\mathrm{a}}$ \\ ${ }^{a}$ State Key Laboratory for Mechanical Behaviour of Materials, Xi' an Jiaotong University, Xi' an 710049, P. R. China \\ ${ }^{\mathrm{b}}$ School of Materials Science and Engineering, Shaanxi University of Technology, Hanzhong Shaanxi 723003, P. R. China
}

MS received 6 April 2011; revised 6 August 2011

\begin{abstract}
Gel fibres of mullite precursor were prepared from an aqueous solution of aluminum nitrate (AN), aluminum isopropoxide (AIP) and tetraethylorthosilicate (TEOS). A 4:1 molar ratio of aluminum isopropoxide and aluminum nitrate was optimized to obtain spinnable precursor sol for synthesis of fibres. Thermogravimetrydifferential scanning calorimetry (TG-DSC), Fourier transform infrared (FTIR) spectra and X-ray diffraction (XRD) analyses were used to characterize properties of the gel and ceramic fibres. The precursor gel completely transformed to mullite at $1200^{\circ} \mathrm{C}$. The activation energy of mullite crystallization was $993.5 \mathrm{~kJ} / \mathrm{mol}$ by the Kissinger equation.
\end{abstract}

Keywords. Mullite; fibres; sol-gel method; activation energy.

\section{Introduction}

Mullite $\left(3 \mathrm{Al}_{2} \mathrm{O}_{3} \cdot 2 \mathrm{SiO}_{2}\right)$ has been recognized as an outstanding ceramic material, for its high temperature strength, creep resistance, thermal and chemical stability, low thermal expansion coefficient and good dielectric properties (Schneider et al 2008; Tan et al 2010). An important potential application of mullite is as fibre reinforcement. In the $\mathrm{Al}_{2} \mathrm{O}_{3}-\mathrm{SiO}_{2}$ system, only mullite exists as the stable compound, which occupies the structure of edges-shared $\mathrm{AlO}_{6}$ octahedron chains parallel to $c$-axis bounded by aluminum and/or silicon tetrahedron (Esther et al 2007; Tan et al 2010).

Main processes for the manufacture of ceramic fibres can be classified as melt-spinning processes and sol-gel spinning processes (Zhang et al 2009). Usually, the melt-spinning method was adopted for the synthesis of ceramic fibres with low melting point. So, the method was not suitable for the preparation of mullite fibres.

Many successful processes have been reported in the preparation of mullite fibres by the sol-gel method (Okada et al 1998; Chen and Gu 2009; Tan et al 2010). Continuous mullite fibres can be obtained using aluminum isopropoxide (AIP) as Al source, with smooth surface and dense microstructure, for AIP polymerization was responsible for the appropriate spinning viscosity (Chen and Gu 2009). Since the expensive AIP was involved in the synthesis process of mullite fibres, the process limits to its widespread applications. In order to reduce the amount of AIP, aluminum nitrate was added in preparation of precursor gel.

\footnotetext{
*Author for correspondence (hb-t@163.com)
}

The activation energy of mullitization has been reported by many workers, but the value may be affected by raw materials category. Some reported that mullitization occurs by nucleation-growth mechanisms. There are, however, different opinions on the rate-controlling step of mullitization (Okada 2008). The activation energies values of mullitization occurs by nucleation-growth which was smaller than the value by rate-controlling (Okada 2008). According to the value of activation energy, mullitization mechanisms can be obtained.

In this work, gel fibres of mullite precursor were prepared from an aqueous solution of aluminum nitrate (AN), AIP and tetraethylorthosilicate (TEOS). And the mullitization behaviour of the mullite precursor gel fibres was determined by non-isothermal experiments, by the analysis of differential scanning calorimetry (DSC) data for samples heated at different heating rates.

\section{Experimental}

\subsection{Preparation of samples}

Starting materials used were AN (Chemical grade, Xi'an reagent factory, Xi'an, China), AIP (Chemical grade, Sinopharm Chemical Reagent Co. Ltd, Shanghai, China) and TEOS (Chemical grade, Tianjin Kermel Chemistry Co. Ltd., Tianjin, China).

Mullite precursor solution was prepared by mixing $\mathrm{H}_{2} \mathrm{O}$, aluminum nitrate, AIP and TEOS were stirred vigorously at room temperature until clear solution was observed. Then the precursor solution was concentrated to obtain spinning 
sol in water bath $\left(80^{\circ} \mathrm{C}\right)$. The sol fibres were prepared by pulling a thin glass rod slowly from the sol after immersing. Then the sol fibres were dried at $60^{\circ} \mathrm{C}$ for $24 \mathrm{~h}$ in an oven. The gel fibres were then sintered at various temperatures between 800,1000 and $1200^{\circ} \mathrm{C}$ for $1 \mathrm{~h}$, with a heating rate of $2{ }^{\circ} \mathrm{C} / \mathrm{min}$.

\subsection{Characterization techniques}

The viscosity measurement of sol was carried out at room temperature by using a NDJ-8 viscometer (Shanghai Fangrui Instrument Co., Ltd, Shanghai, China) at a shear rate $3 \mathrm{r} / \mathrm{min}$. For the gel fibres, thermal behaviour was measured by thermogravimetry-differential scanning calorimetry (TG/DSC) instruments (SDT Q600, TA Instrument, America) at a heating rate of $5,10,15$ and $20^{\circ} \mathrm{C} / \mathrm{min}$ in flowing air, and Fourier transform infrared (FTIR) spectra was recorded on 6700 Infrared Spectrometer (Nicolet Magna, America) with the samples as $\mathrm{KBr}$ pellets. X-ray diffraction analysis was carried out on a DX-2500 X-ray diffractometer (XRD, Dandong Fangyuan, Dandong, China) using $\mathrm{CuK} \alpha$ radiation, and a step width of $0.05^{\circ} / \mathrm{s}$. Microstructure feature was observed under a JSM-6390LV scanning electron microscope (SEM) instrument (JEOL, Japan). All tests were done at room temperature.

\section{Results and discussion}

\subsection{Characterization of precursors}

Some properties of the sols prepared with different amounts of AIP are shown in table 1. The spinning sol could be obtained when the ratio of AIP and AN was 5:1 and 4:1, respectively. AIP has not participated in hydrolysis and condensation polymerization reaction without adding $\mathrm{AN}$, the sols have no spinnablity (Chen and Gu 2009). The acidic solution can be obtained by adding $\mathrm{AN}$, then the $\mathrm{M}-\mathrm{OH}$ monomer (where $\mathrm{M}$ is defined as metal $\mathrm{Al}$ or $\mathrm{Si}$ ) was obtained, when the hydrolysis of AIP or TEOS took place. The polymer chains of $\mathrm{M}-\mathrm{O}-\mathrm{M}$ and $\mathrm{M}-\mathrm{OH}-\mathrm{M}$ were present while the condensation polymerization of $\mathrm{M}-\mathrm{OH}$ monomer took place (Chen and Gu 2009). So, the spinnable sols were obtained.

Table 1. Effects of AIP and AN ratio on sols spinnable property*.

\begin{tabular}{lccc}
\hline Sol & AIP:AN (mol) & Appearance of sol & Spinnability of sol \\
\hline 1 & $5: 1$ & Transparent & Preferable \\
2 & $4: 1$ & Transparent & Preferable \\
3 & $3: 1$ & Transparent & Able \\
4 & $2: 1$ & Transparent & Unable \\
\hline
\end{tabular}

*AIP, aluminum isopropoxide; AN, aluminum nitrate.
The spinnability of the sol was remarkably dependent on the added content of AN. With the increase of the content of $\mathrm{AN}$, the sol spinnability reduced because $\mathrm{pH}$ value of sol decreased. As a result, the content of polymer chains (M-O-M and $\mathrm{M}-\mathrm{OH}-\mathrm{M}$ ) decreased in precursor sol (Shojaie-Bahaabad et al 2008). The sol did not have spinnability, with a 2:1 ratio of AIP and AN.

According to the cost and spinnability of precursor sol, the sol (Tan et al 2010) was suitable for fibres preparation, when the molar ratio of AIP and AN was 4:1 in the sol. When the viscosity of sol (Tan et al 2010) was about $8602 \mathrm{mPa} \mathrm{s}$, long gel fibres were obtained having $20 \mathrm{~cm}$ length. The length and diameter of fibres were influenced by viscosity and surface tension of spinning sol, speed of hand drawing and so on. Further research about these factors is being carried out.

TG/DSC curves of the mullite precursor gel are shown in figure 1 , with a heating rate of $10{ }^{\circ} \mathrm{C} / \mathrm{min}$. DSC curve of the gel fibres exhibited two endothermic peaks at about $160^{\circ} \mathrm{C}$ and $300^{\circ} \mathrm{C}$, and two exothermic peaks at about $500^{\circ} \mathrm{C}$ and $983^{\circ} \mathrm{C}$. The two endothermic peaks are assigned to dehydration of the residual water and decomposition of hydroxides in the gel fibres, whereas two exothermic peaks are assigned to decomposition of organic component and crystallization of mullite, respectively. TG curve of the gel fibres showed weight loss around $43 \mathrm{wt} \%$ at $400{ }^{\circ} \mathrm{C}$, while almost no further weight loss appeared with increasing temperatures.

In the above thermal analysis, the most interesting phenomenon is the intensity of the exothermic peak at $983^{\circ} \mathrm{C}$. Sharp $983^{\circ} \mathrm{C}$ exothermic peak indicated better homogeneity of the $\mathrm{Al}$ and $\mathrm{Si}$ components at a molecular scale (Lee et al 2002; Douy 2006), which will be beneficial for obtaining mullite phase at lower temperature.

FTIR spectra of mullite precursor gel and calcined fibre are shown in figure 2. As can be seen, the band at $1636 \mathrm{~cm}^{-1}$ is assigned to the $\mathrm{OH}$ bending mode. The band at $1384 \mathrm{~cm}^{-1}$ and $1353,1384 \mathrm{~cm}^{-1}$ are assigned to the $\mathrm{CH}_{2}, \mathrm{CH}_{3}$ stretching modes, respectively, which were obtained because AIP and TEOS hydrolyzed. The bands observed at $970 \mathrm{~cm}^{-1}$ and $560 \mathrm{~cm}^{-1}$ correspond to Al-O bonding modes. The band observed at $830 \mathrm{~cm}^{-1}$ and $430 \mathrm{~cm}^{-1}$ corresponds to $\mathrm{O}-\mathrm{Si}-\mathrm{O}$ stretching mode and bonding modes, respectively.

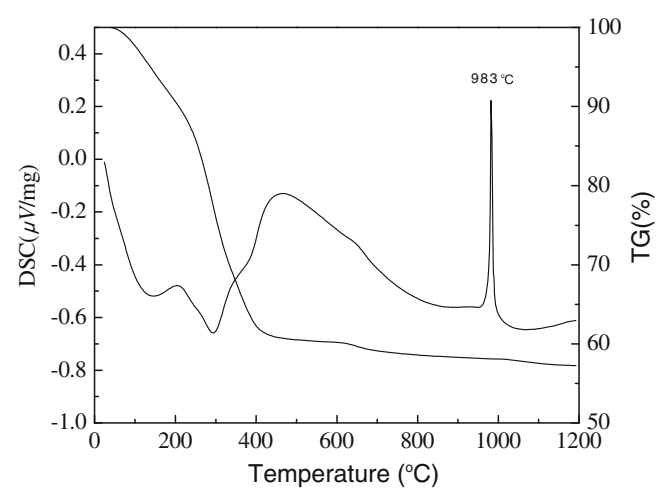

Figure 1. TG and DSC curves of mullite precursor gel fibres. 


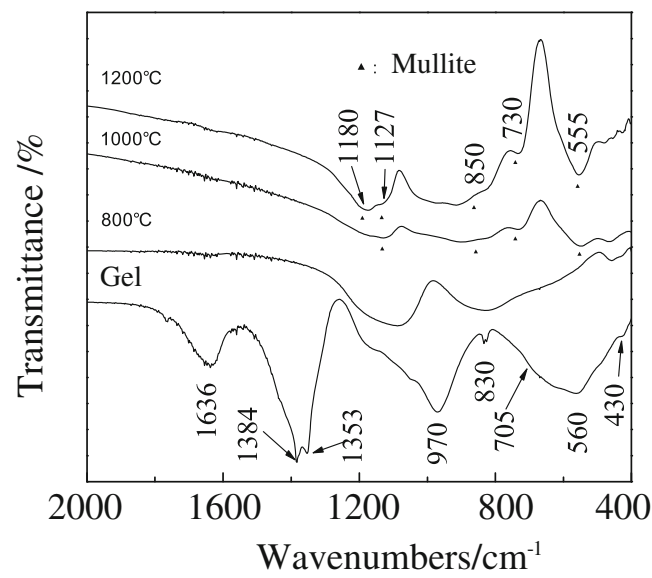

Figure 2. FT-IR spectra of mullite precursor gel fibres and fibres heated at 800,1000 and $1200^{\circ} \mathrm{C}$ for $1 \mathrm{~h}$.

The band at $560 \mathrm{~cm}^{-1}$ has a shoulder around $705 \mathrm{~cm}^{-1}$, which is may be assigned to the ( $\mathrm{Si}, \mathrm{Al})-\mathrm{O}-(\mathrm{Si}, \mathrm{Al})$ linkages bending modes. This assignment is in agreement with the proposed $(\mathrm{Si}, \mathrm{Al})-\mathrm{O}-(\mathrm{Si}, \mathrm{Al})$ bending mode for the band at $737 \mathrm{~cm}^{-1}$ in mullite (Beran et al 2001). The polymer chains of $\mathrm{Si}-\mathrm{O}-\mathrm{Si}, \mathrm{Al}-\mathrm{O}-\mathrm{Al}$ and $\mathrm{Al}-\mathrm{O}-\mathrm{Si}$ were obtained by hydrolysis and condensation polymerization of AIP and TEOS.

The bands at $1636 \mathrm{~cm}^{-1}$ and $1383 \mathrm{~cm}^{-1}$ were not detected from the specimen which was calcined at $800^{\circ} \mathrm{C}$. The result indicated that organic substance and water had evaporated.

The spectra of mullite are clearly observed in the gel calcined at $1000^{\circ} \mathrm{C}$ and $1200^{\circ} \mathrm{C}$, and show bands at 1100 $1200 \mathrm{~cm}^{-1}$ due to $\mathrm{AlO}_{4}$ and $\mathrm{SiO}_{4}$ species. In the region 800-900 $\mathrm{cm}^{-1}$, they are mainly associated with $\mathrm{AlO}_{4}$ and $\mathrm{AlO}_{6}$ species; at $730 \mathrm{~cm}^{-1}$, it is due to $\mathrm{AlO}_{4}$ species; and at $550 \mathrm{~cm}^{-1}$, it is corresponding to $\mathrm{AlO}_{6}$ species (Song 1998). The infrared spectra show that the formation of mullite begins at $1000^{\circ} \mathrm{C}$.

When the chemical composition of mullite is rich in $\mathrm{Al}_{2} \mathrm{O}_{3}$, the $1127 \mathrm{~cm}^{-1}$ peak is stronger than the $1180 \mathrm{~cm}^{-1}$ peak in intensity. As can be seen, in the sample sintered at $1000^{\circ} \mathrm{C}$, the $1127 \mathrm{~cm}^{-1}$ peak was stronger than that at $1180 \mathrm{~cm}^{-1}$. But in the sample sintered at $1200^{\circ} \mathrm{C}$, the $1127 \mathrm{~cm}^{-1}$ peak was weaker than that at $1180 \mathrm{~cm}^{-1}$. This fact suggests the initial formation of an $\mathrm{Al}_{2} \mathrm{O}_{3}$-rich mullite and reflects the change in chemical composition of mullite.

X-ray diffraction patterns of JCPDS Card \#15-0776 and the mullite precursor gel fibres heated at 800, 1000 and $1200^{\circ} \mathrm{C}$ are shown in figure 3 . Only amorphous phase was present when fibres were sintered at $800^{\circ} \mathrm{C}$. Mullite phase was obtained in the samples sintered at $1000^{\circ} \mathrm{C}$, while only mullite phase was observed at $1200^{\circ} \mathrm{C}$. XRD peak lines of fibres were not nearly shifted compared with JCPDS Card \#15-0776. From the DSC and XRD analysis results, it can be concluded that mullitization of the gel occurred at temperature of about $1000^{\circ} \mathrm{C}$.

Mullite formed at $980^{\circ} \mathrm{C}$ is always richer in alumina than the bulk precursor. It has been called 'tetragonal mullite'

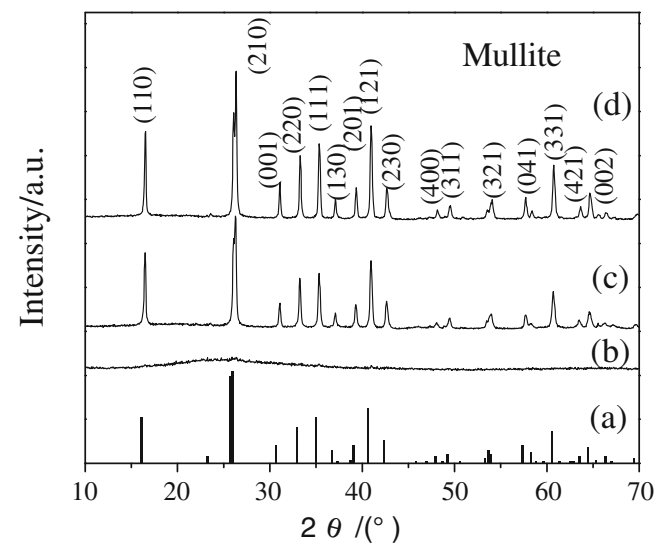

Figure 3. XRD patterns of (a) JCPDS Card \#15-0776, mullite, and mullite precursor gel fibres heated at (b) 800, (c) 1000 and (d) $1200^{\circ} \mathrm{C}$ for $1 \mathrm{~h}$.

but in fact has an orthorhombic structure with cell parameters $a$ and $b$ being very close. By increasing the temperature, a progressive contraction of the $a$-parameter indicating a decrease of the alumina content, is generally observed and a composition very close to $3 \mathrm{Al}_{2} \mathrm{O}_{3} \cdot 2 \mathrm{SiO}_{2}$ is reached (Douy 2006).

The mullitization temperature was considered to be an important criterion in the assessment of the mixing scale of $\mathrm{Al}$ and $\mathrm{Si}$ components in the gels. When the scale of chemical homogeneity is at the atomic level, mullite formation is observed at about $980^{\circ} \mathrm{C}$ (Leivo et al 2009). In contrast, when the scale of chemical homogeneity is in the nanometer range (the so-called diphasic precursors), formation of mullite is delayed due to temperatures higher than $1200^{\circ} \mathrm{C}$ (Sales and Alarch 1996). Tkalcec et al (2005) obtained mullite phase at a sintering temperature of $1200-1300^{\circ} \mathrm{C}$ using diphasic aluminosilicate gels. Temperatures in the range of $1600-1700{ }^{\circ} \mathrm{C}$ are required to achieve complete mullitization by mixing alumina and silica particles in the micrometer size range (Song 1998). The start transformation to mullite was obtained at $983^{\circ} \mathrm{C}$ in this experiment. So, conclusion can be obtained that the $\mathrm{Si}$ and $\mathrm{Al}$ were mixed at a molecular level in the precursor gel.

SEM micrographs of mullite fibres calcined at $1200^{\circ} \mathrm{C}$ are shown in figure 4 . The diameter of these fibres is about $20 \mu \mathrm{m}$, with a smooth surface and uniform diameter.

When the gel fibres were dried and sintered, some gas could be produced for dehydration of the residual water and decomposition of hydroxides and organic component. Some micropores were formed in fibres in order to eliminate gas. After sintering at $1200^{\circ} \mathrm{C}$, the micropores were not observed because the fibre structure became dense.

\subsection{Activation energy}

The activation energy $\left(E_{\mathrm{a}}\right)$ of mullitization can be determined by isothermal or non-isothermal method. Under nonisothermal conditions, DSC or DTA curves were used to 

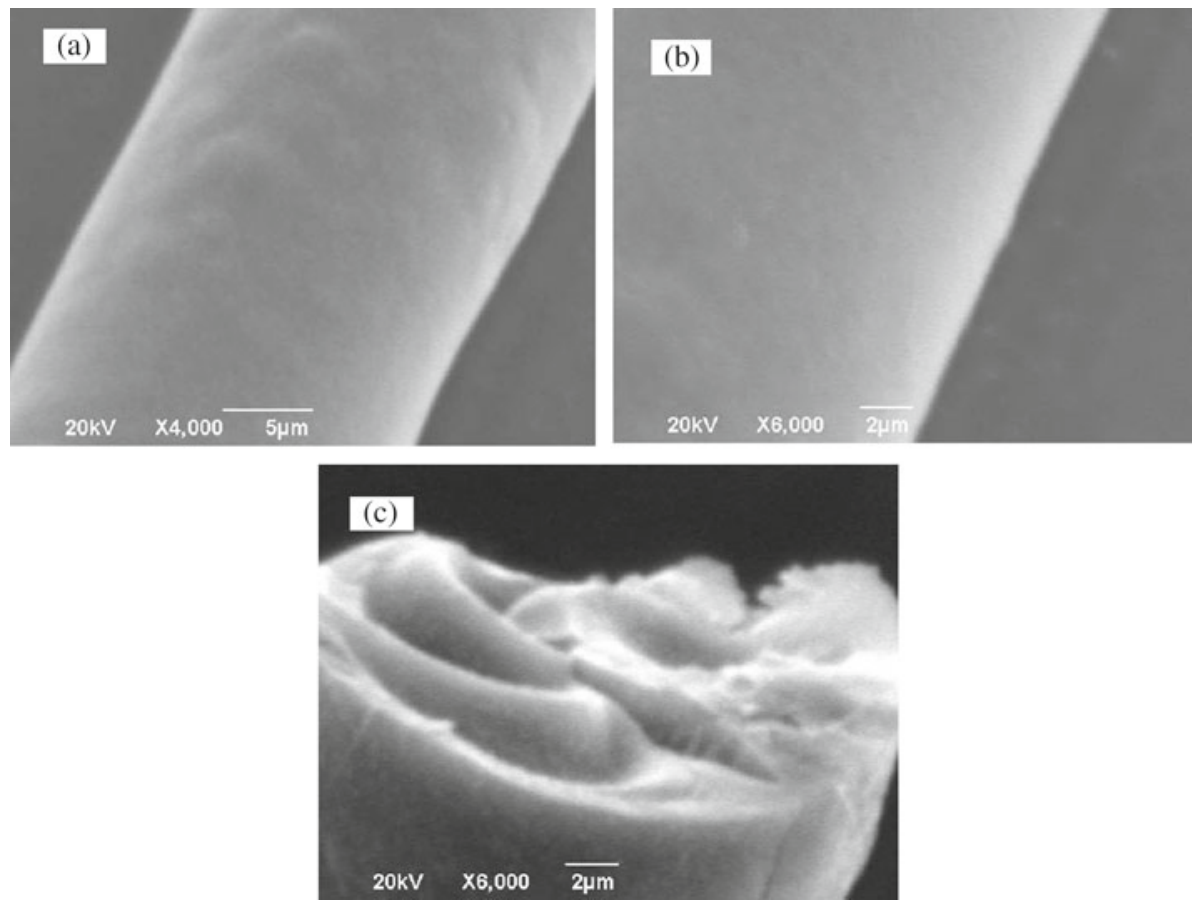

Figure 4. SEM microstructures of mullite fibres heated at $1200^{\circ} \mathrm{C}$ for $1 \mathrm{~h}$.

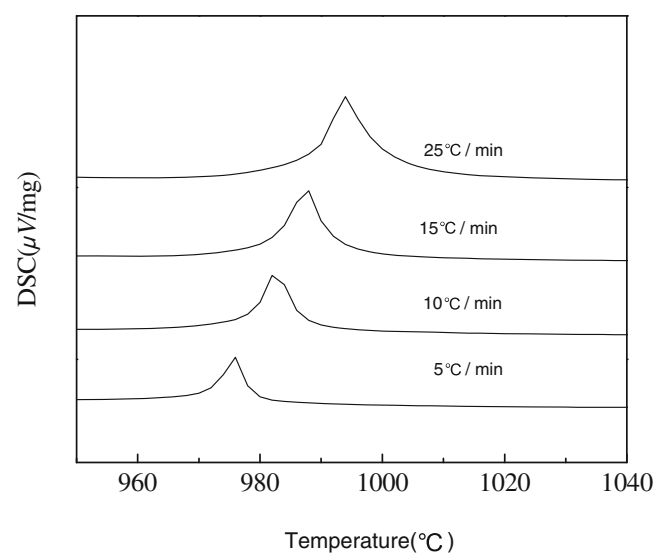

Figure 5. DSC curves of mullite precursor gel fibres at different heating rates.

obtain $E_{\mathrm{a}}$ values from peak temperature measurements at different heating rates. A non-isothermal method was experimentally easier than an isothermal method, but the accuracy of the resulting $E_{\text {a }}$ value was generally strongly influenced by experimental conditions such as particle size, particle distribution, packing state, etc (Okada 2008; Tan et al 2010). In general, using larger sample sizes and faster heating rates may result in a reduction in the accuracy of activation energy (Okada et al 2003; Campos et al 2005).

Figure 5 shows thermograms obtained for DSC runs with heating rates of $5,10,15$ and $20^{\circ} \mathrm{C} / \mathrm{min}$ for precursors. The exothermic peak, in the range of $976-994^{\circ} \mathrm{C}$, corresponds to mullite crystallization.

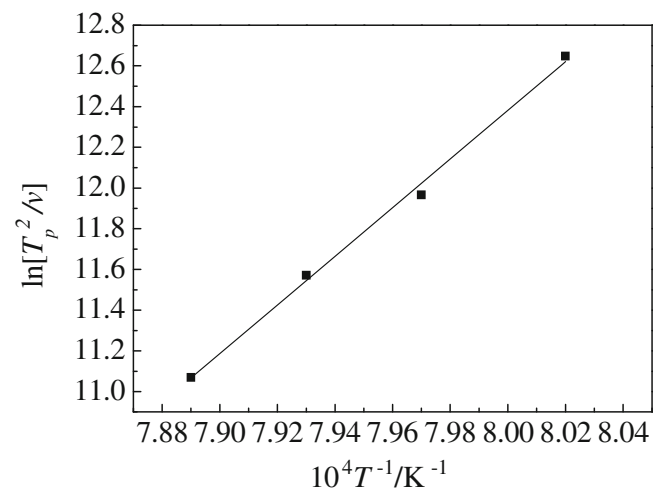

Figure 6. Activation energy plot for mullitization, according to (1).

Although many mathematical equations had been proposed for the calculations, the Kissinger equation (1) was most commonly used (Okada 2008).

$$
\ln \left(\frac{T_{\mathrm{p}}^{2}}{v}\right)=\ln \left(\frac{E_{\mathrm{a}}}{R}\right)-\ln \phi+\frac{E_{\mathrm{a}}}{R T_{\mathrm{p}}},
$$

where $T_{\mathrm{p}}$ is the temperature of the exothermic peak top (crystallization temperature), $v$ the heating rate, $E_{\mathrm{a}}$ the activation energy, $R$ the universal gas constant and $\phi$ the frequency factor (it is a constant dependent of the sample).

According to (1), by plotting of $\ln \left(T_{\mathrm{p}}^{2} / \nu\right)$ vs $1 / T_{\mathrm{p}}$, the activation energy can be determined from the slope. As can be shown in figure 6 , the value $E_{\mathrm{a}}=993.5 \mathrm{~kJ} / \mathrm{mol}$ was determined. 
Table 2. Activation energy of mullitization reported by different authors.

\begin{tabular}{lcc}
\hline Authors & Starting materials & $\begin{array}{c}\text { Activation energy } \\
(\mathrm{kJ} / \mathrm{mol})\end{array}$ \\
\hline Lee et al & Monophasic gel & 1394 \\
Tkalcec et al & Diphasic gel & $1119 \pm 25$ \\
Okada et al & Monophasic gel & $1202 \pm 27$ \\
Tkalcec et al & Monophasic gel & $1053 \pm 51$ \\
Chen et al $(2004)$ & Kaolinite $+\mathrm{Al}_{2} \mathrm{O}_{3}$ & 1182 \\
\hline
\end{tabular}

The $E_{\mathrm{a}}$ values are consistent with the data reported by Tkalcec et al (1998) which obtained the value by isothermal differential scanning calorimetry using single-phase gel. But, $E_{\mathrm{a}}$ values are smaller than the other reported data listed in table 2, where data also were obtained using monophasic gel. This conflicting result can be explained as follows. The experimental conditions used by different authors are inconsistent, such as particle size, particle distribution, packing state, etc.

The nucleation-growth controls mullitization, when direct crystallization from an amorphous phase occurs in the low temperature range $\left(900-1000^{\circ} \mathrm{C}\right.$ ) and the $E_{\mathrm{a}}$ values are high (900-1400 kJ/mol). So, mullitization occurred by nucleation-growth mechanisms in this work, and the pathway of mullite formation was direct formation of Al-rich mullite at about $1000^{\circ} \mathrm{C}$.

\section{Conclusions}

Mullite gel fibres have been prepared using AN, AIP and TEOS as starting materials. The molar ratio of AIP and AN of 4:1 was optimal proportion to obtain spinnability of the sols. Only amorphous phase was present when fibres were sintered at $800^{\circ} \mathrm{C}$ and complete mullitization temperature was at $1200^{\circ} \mathrm{C}$.

The activation energy for mullite formation in precursor gel fibres was determined by means of differential scanning calorimetry. The $E_{\mathrm{a}}$ value was $993.5 \mathrm{~kJ} / \mathrm{mol}$ by Kissinger equation.

\section{Acknowledgements}

This work was supported by the National Natural Science Foundation of China (No. 50772086, 50821140308), the High-Tech R \& D Program of China (863, No. 2007AA03Z558), Shaanxi Natural Science Foundation of China (No. 2012JQ6017) and Shaanxi University of Technology Foundation of China (SLGQD1101).

\section{References}

Beran A, Voll D and Schneider H 2001 J. Eur. Ceram. Soc. 21 2479

Campos A L, Kawachi E Y, Oliwera T C and Thim G P 2005 Mater. Sci. Eng. B112 169

Chen X and Gu L 2009 J. Mater. Proc. Technol. 2093991

Chen Y-F, Wang M-C and Hon M-H 2004 J. Eur. Ceram. Soc. 24 2389

Douy A 2006 J. Eur. Ceram. Soc. 261447

Esther R S, Francisco J S, Estefania D-P, Maria M R, Pardo A I, Kojdecki M A, Amigo J M and Alarcon J 2007 J. Eur. Ceram. Soc. 272647

Lee J-E, Kim J-W, Jung Y-G, Jo C-Y and Paik U 2002 Ceram. Int. 28935

Leivo J, Lindén M, Ritola M, Vippola M, Levanen E and Mantyla T A 2009 Mater. Chem. Phys. 11556

Okada K 2008 J. Eur. Ceram. Soc. 28377

Okada K, Yasohama S, Hayashi S and Yasumori A 1998 J. Eur. Ceram. Soc. 181879

Okada K, Kaneda J, Kameshimaa Y, Yasumori A and Takei T 2003 Mater. Lett. 573155

Sales M and Alarch J 1996 J. Eur. Ceram. Soc. 16781

Schneider H, Schreuer J and Hildmann B 2008 J. Eur. Ceram. Soc. 28329

Shojaie-Bahaabad M, Taheri-Nassaj E and Naghizadeh R 2008 Ceram. Int. $\mathbf{3 4} 1893$

Song K C 1998 Mater. Lett. 35290

Tan H, Ding Y and Yang J 2010 J. Alloys Compd 492396

Tkalcec E, Nass R, Schmauch J, Schmidt H, Kurajica S, Bezjak A and Ivankovic H 1998 J. Non-Cryst. Solids 22357

Tkalcec E, Kurajica S and Ivankovic H 2005 J. Eur. Ceram. Soc. 25 613

Zhang Y, Ding Y, Gao J and Yang J 2009 J. Eur. Ceram. Soc. 29 1101 